\title{
EDUCAÇÃO NO CAMPO: gestão democrática presente na pedagogia do Movimento dos Trabalhadores Rurais Sem Terra (MST)
}

\section{EDUCATION IN THE FIELD: democratic management present in the pedagogy of the Movement of Rural Workers without Earth (MST)}

\author{
Alba Regina Azevedo Arana \\ Universidade do Oeste Paulista, Programa de Pós Graduação em meio Ambiente e Desenvolvimento \\ Regional, Unoeste, Presidente Prudente-SP, Brasil \\ alba@unoeste.br \\ Fernanda Serrano Fernandes \\ Universidade do Oeste Paulista, Faculdade de Ciências Letras e Educação de Presidente Prudente- \\ FACLEPP- Unoeste. Presidente Prudente- SP. Brasil Endereço: \\ fe-csfernandes@hotmail.com
}

\section{Resumo}

Esse artigo tem por objetivo analisar o sentido da gestão democrática presente na Pedagogia do Movimento dos Trabalhadores Rurais Sem Terra para a educação infantil. A problemática recai em discutir: Em que medida a proposta pedagógica do MST para a educação infantil avança na concretização do princípio constitucional da gestão democrática? Para responder a problemática foi realizada pesquisa bibliográfica e documental, fundamentada em autores que discutem a temática e documentos coletados no sítio do MST. Os resultados obtidos indicam que embora ainda existam muitos desafios em relação a implementação da proposta de Educação para as Escolas do Campo, bem como para a efetivação da Pedagogia do Movimento nas Escolas do MST, a proposta é coerente com os princípios defendidos e com o discurso político e social materializado na luta do Movimento.

Palavras-chave: Gestão democrática. Educação do Campo. Movimentos Sociais. Educação Infantil.

\begin{abstract}
Abstrat
This article aims to analyze the meaning of democratic management present in the Pedagogy of the Landless Rural Workers' Movement for early childhood education. The problem lies in discussing: To what extent does the MST's pedagogical proposal for early childhood education advance the realization of the constitutional principle of democratic management? To answer the problem, a bibliographic and documentary research was carried out, based on authors who discuss the subject and documents collected on the MST site. The results indicate that although there are still many challenges regarding the implementation of the Education for the Field Schools proposal, as well as for the implementation of Movement Pedagogy in the MST Schools, the proposal is consistent
\end{abstract}


with the principles defended and the discourse political and social reality embodied in the struggle of the Movement.

Keywords: Democratic management. Field Education. Social Movements. Child Education

\section{Introdução}

Embora nos últimos anos tenha-se avançado na democratização da educação no país, ainda é comum encontrarmos o cenário da falta de oferta da educação infantil para as crianças de 0 a 3 anos de idade, período no qual deveriam ser atendidas na creche; bem como para as crianças de 4 a 5 anos da pré-escola - estas sozinhas somam, segundo a apresentação do Censo Escolar 2017 realizado pelo Instituto Nacional de Estudos e Pesquisas Educacionais Anísio Teixeira (INEP), pouco mais de 821 mil crianças que não frequentam a escola (BRASIL, 2017a).

A situação, agravada pela inexistência de escolas de educação infantil nas áreas de assentamentos, faz com que as crianças enfrentem horas no percurso entre a casa, localizada na zona rural, e a escola, em geral localizada no perímetro urbano, e ainda contribui para que as mesmas, muitas vezes sejam estigmatizadas como "atrasadas", desprovidas de educação e cultura em relação ao urbano (BARBOSA et al., 2012). Isso ocorre apesar: do assentamento ser resultado da luta pela terra; da educação no campo ser alvo de luta pelos movimentos sociais camponeses; de existir uma proposta educacional própria para as escolas do campo, em especial, do MST; e de haver, em âmbito federal, orientações oficiais para as escolas do campo.

A falta de oferta de escolas de educação infantil, bem como os desafios da educação infantil para as crianças do campo foram analisados nas pesquisas de Barbosa et al. (2012) e Arroyo, Caldart e Molina (2011). Tais estudos indicaram a dissonância entre as orientações oficiais propagadas pela política educacional e a efetivação da mesma. Diante dos desafios postos para a efetivação da educação infantil no campo e dos avanços teóricos e metodológicos obtidos pelo MST na proposta pedagógica para educação infantil, suscitou a necessidade de compreender a proposta de gestão democrática na educação infantil do Movimento dos Trabalhadores Rurais Sem Terra. 
Elegemos o princípio da gestão democrática porque ele é um pilar fundamental da proposta educacional do MST, bem como é um princípio constitucional a ser assimilado por todas as escolas da rede pública do país, conforme legislação específica (BRASIL, 1988). Nessa perspectiva, a questão investigativa da pesquisa está em saber: Qual o sentido da proposição da gestão democrática nas escolas de Educação Infantil do MST?

Desta forma, este artigo tem como objetivo evidenciar os meios de efetivação da gestão democrática por um dos movimentos sociais de maior expressão na América Latina, o qual conseguiu sistematizar e materializar uma proposta educacional condizente com os princípios defendidos no processo de luta pela reforma agrária (DAL RI; VIEITEZ, 2004). E ainda, apresentar as orientações educacionais advindas do MST para a educação infantil e a proposição da política pública para o campo. Esse fato permite perceber uma dimensão da relação que se estabelece entre Estado e movimentos sociais, no caso o MST, na definição de orientações para a Educação do Campo. Esse aspecto evidencia, ainda, o campo de tensão entre movimento social e Estado, tal como apontou Caldart (2009).

Desse modo, a hipótese adotada é de que a Pedagogia do MST, apresenta mecanismos concretos e inovadores de materialização do princípio constitucional "gestão democrática da escola pública, na forma da lei”, principalmente porque conta com a intensa atuação das crianças na organização da escola.

O caminho metodológico para tanto é a pesquisa bibliográfica e documental, de abordagem qualitativa, analisando as produções de alguns autores que discutem o tema e foram evidenciados anteriormente; bem como documentos oficiais produzidos em âmbito federal sobre Educação Infantil e os de natureza do MST, como Cadernos e Boletins produzidos pelo Setor de Educação do Movimento, disponibilizados no sitio do mesmo. De acordo com Gil (2008), tal caminho permite o conhecimento do passado; possibilita investigar os processos de mudança social e cultural; e ainda, segundo Chizzotti (2003, p. 79) considera a "relação dinâmica entre o mundo real e o sujeito".

\section{O movimento pela educação do/no campo: notas de uma construção}

A origem da organização escolar para as áreas rurais estiveram durante muitos anos vinculadas à matrizes culturais correspondentes a colonização, escravidão e 
latifúndio, pautadas no contexto do desenvolvimento das estruturas socioagrárias e das revoluções agroindustriais, sendo conduzida ao longo da história de forma desinteressada e descontinuada, indo ao encontro dos interesses dominantes e contra a classe dos trabalhadores rurais que deveriam permanecer na servidão e na ignorância (CALAZANS, 1993, SILVA; MORAIS; BOF, 2006).

No âmbito de discursos desenvolvimentistas e urbanizadores, o campo era entendido como espaço a ser superado pelos centros urbanos, pois desconsiderava-o como espaço de vida e de construção de sujeitos cidadãos. Essa compreensão impossibilitou a formulação de diretrizes políticas e pedagógicas específicas, além de recursos financeiros para a institucionalização e manutenção de escolas em áreas rurais (RAMOS; MOREIRA; SANTOS, 2004).

No entanto, com o desenvolvimento agroindustrial, o Estado entende ser necessário escolarizar o meio rural para instrumentalizar e reproduzir sua estrutura hegemônica, além de conter o fluxo migratório do campo para a cidade em consequência da violência e degradação de vida dos trabalhadores rurais (SILVA; MORAIS; BOF, 2006).

Entretanto, as escolas existentes no campo vivenciavam uma série de problemas relacionados à infraestrutura, corpo docente, proposta pedagógica, ensino multisseriado, entre outros. Francisco e Alaniz (2014, p.40) expressam essa problemática da "primazia pelo trabalho manual em oposição ao intelectual", em que o modelo de escola oficial ofertado para a população rural é negado por ser precário, multisseriado e alheio à realidade do campo. Explicitando, dessa forma a despreocupação do Estado em relação à educação dos camponeses.

A chegada do regime ditatorial causa um retrocesso nas políticas educacionais em decorrência ao fechamento dos canais de participação e representatividade que proporcionavam avanços, acarretando repressões, sobretudo para líderes de movimentos sociais, educadores e universidades. Contudo, nas décadas de 1970 e 1980, os movimentos sociais e culturais reiniciam a luta pela democratização da sociedade, pela conscientização popular e reivindicam direitos sociais. Tal processo desencadeia na sociedade uma reflexão crítica acerca da relação educação escolar e formação para o trabalho (RAMOS; MOREIRA; SANTOS, 2004). 
As escolas ocupadas pelo MST elucidam a proposição de escola do e no campo, afinada com a ideologia e prática do movimento social, como forma de efetivar o direito à educação presente na Constituição Federal (CF) de 1988. A escola proposta pelo MST, segundo Francisco e Alaniz (2014, p. 47), fundamenta-se na gestão coletiva e democrática da escola; na atuação de alunos, professores e comunidade; no trabalho produtivo e associado com a prática pedagógica, e na atuação desde a educação infantil, visando a formação para a militância. O Movimento, ao ocupar parcialmente ou totalmente a escola pública, transformando-a em Escola do Campo, sinaliza o antagonismo para com as escolas estatais oficiais.

Vale ressaltar que a CF/1988 afirma o direito à educação ao tratá-la como direito público subjetivo, como também a Lei 9.394/96 de Diretrizes e Bases da Educação Nacional (LDBEN), especificamente no art. 28, menciona o respeito às especificidades da educação na área rural (BRASIL, 2016). Entretanto, muitas vezes, tais legislações são desconsideradas quando predomina, na prática, o fechamento de escolas no campo (SOUZA, 2008), o deslocamento das crianças para escolas da cidade e a concepção urbana de educação mesmo quando tais escolas encontram-se na área rural.

Embora o Ministério da Educação (MEC) tenha assumido o compromisso de disseminar as Diretrizes Operacionais para os Estados e municípios, bem como verificar falhas na implantação da proposta de adequação dos projetos nas instituições que integram os diversos sistemas de ensino e apresentar orientações que contribuam para garantir o atendimento com qualidade às populações do campo, o Parecer $\mathrm{CNE} / \mathrm{CEB} \mathrm{n}^{\mathrm{o}}$ 23/2007 traz em seu relatório indícios que apontam que as políticas de nucleação e de transporte escolar acabam descaracterizando a proposta (BRASIL, 2007).

Diante das exposições presentes no referido documento, a Câmara de Educação Básica do Conselho Nacional de Educação estabelece por meio da Resolução CNE/CEB $\mathrm{n}^{\circ}$ 2, de abril de 2008, as Diretrizes Complementares de atendimento da Educação Básica do Campo, provendo um conjunto de normas e princípios para o desenvolvimento de políticas públicas que realmente considerem as especificidades e necessidades do campo (BRASIL, 2008).

Ainda que a relação entre Estado e movimentos sociais seja contraditória e perpassada pela oposição de concepções e de práticas político-pedagógicas, como indicou Caldart (2009), a entrada da educação do campo na agenda governamental pela pressão 
do movimento camponês é uma importante conquista relacionada à efetivação do direito à educação (RIBEIRO, 2012).

Pesquisas destinadas a analisar algumas experiências empíricas de escolas do MST, entre elas as realizadas por Caldart (2013); Dal Ri e Vieitez (2004, 2008, 2010); Arenhart (2007); Da Mata (2015) e Souza (2008), indicam que a prática da gestão democrática, por meio do autogoverno ou auto-organização dos estudantes, é uma característica fundamental da organização da escola e do trabalho educativo no MST.

\section{A Pedagogia do MST na educação infantil}

O trabalho educativo com crianças no Movimento iniciou com a sensibilização de mães, professoras e voluntárias religiosas que se preocupavam com um atendimento mais pedagógico às crianças objetivando amenizar o peso da realidade e da violência vivenciada por elas nas primeiras ocupações. Brincadeiras, encenações, cantos e desenhos ajudavam a diminuir as tensões da luta ao mesmo tempo em que propiciava às crianças a realização de "leituras" de sua própria história por meio das diversas expressões citadas (CALDART, 2012).

O passo seguinte foi providenciar que as crianças fossem alfabetizadas, o que demandaria organização e luta coletiva por mais recursos. Iniciou aí o primeiro desafio das educadoras e educadores que consistia em mobilizar as famílias para que participassem da luta por escolas. Isso porque alguns pais e membros da direção enxergavam a luta pela terra dissociada das outras dimensões que a vida no campo compreende, e neste caso, apenas a terra era suficiente. O empenho das educadoras e educadores do Movimento em conscientizar esses sujeitos foi fundamental para que os trabalhadores se organizassem e lutassem por escolas junto aos órgãos públicos (CALDART, 2012).

Somado ao apoio dos pais, outro fator importante foi a preocupação dos educadores e educadoras com a qualidade de sua formação e com seu papel articulador na formação de crianças, jovens e adultos. (CALDART, 2012). Diante dessas condições, o MST começa a promover discussões e desenvolver ações, além de sistematizar e registrar suas experiências por meio do Setor de Educação e do Coletivo Nacional de Educação do MST. O processo de elaboração teórica coletiva da proposta pedagógica do 
MST para suas escolas configura-se como "uma ampliação da própria noção de direito: não apenas ter acesso à escola mas também ter o direito de constituí-la como parte da sua identidade: fazer de cada escola conquistada uma escola do MST" (CALDART, 2012, p. 253).

Segundo Caldart (2003, 2012) e Arroyo, Caldart e Molina (2011), o princípio pedagógico presente em todas as experiências educativas de formação dos Sem Terra consiste no próprio movimento de transformar-se transformando pessoas, a história, a terra e a própria pedagogia. Ou seja, o MST enquanto coletivo em movimento produz novos sentidos e referências a cada ação, estrutura ou sujeito que constitua seu cotidiano, compreendendo que o ser humano e o mundo estão para serem feitos, transformados.

A proposta educacional do Movimento vai à contramão dos interesses das classes dominantes e da ordem social capitalista, contrariando a hegemonia e dicotomia presente no ensino público oficial que reproduz desigualdades sociais, ainda que a mesma "apresente-se travestida na forma de conhecimentos, valores e habilidades universais" (DAL RI; VIEITEZ, 2004, p. 44). Dessa forma, percebendo que tal proposta de ensino não atende as necessidades de formação de seus membros e preocupados com a realidade social, o MST formula suas ideias educacionais,

[...] com o propósito de incitar uma formação acadêmica que habilite a população para efetuar uma ação transformadora na sociedade, tendo como perspectiva o fortalecimento da democracia, a cidadania, a igualdade social e até mesmo o socialismo. (DAL RI; VIEITEZ, 2004, p.44).

Em consonância, Da Mata (2015, p. 58) complementa que na proposta oficial de ensino prevalecem valores do mercado pautados, prioritariamente, na lucratividade e competição. Isso contribui para a manutenção e reprodução das "relações de dominação e subordinação dentro do sistema econômico, político, social e cultural, estratificando o ensino por classes sociais, numa perspectiva individualista de exclusão".

A afirmação de que a pedagogia do Movimento não cabe na escola, mas a escola cabe no Movimento, realizada por Caldart (2003, 2012), indica que a escola que temos oficialmente não comporta todas as dimensões da formação humana, bem como não comporta o Movimento, e revela a necessidade de se valorizar outros momentos e vivências que produzem aprendizados bem mais significativos. A escola que cabe no Movimento e é objeto de luta é a que se configura como "oficina de formação humana" 
e "reassume sua tarefa de origem: participar do processo de formação humana" (CALDART, 2003, p. 58).

Dessa forma, é necessário repensar a lógica e os métodos pedagógicos, planejar estratégias pedagógicas diversas dadas a complexidade do processo de formação humana e dos diferentes aprendizados que a compõem.

Arenhart (2003), Caldart (2012) e Ramos (2016) afirmam que a concepção de escola presente no Movimento, constrói-se a partir da educação socialista e possui como matriz formadora e organizadora dessa escola: a luta social (motor do Movimento), o coletivo (dos educadores, dos estudantes, da comunidade), o trabalho (como princípio educativo ligado à vida e não a relações mercadológicas), e a mística (em cultivar o processo histórico, projetando o futuro). A educação socialista de acordo com Freitas (2003 apud CALDART, 2012b, p.282), "propõe uma educação crítica, desnaturalizadora da ordem social, que eduque homens e mulheres para que atuem na direção da construção de outro projeto para a sociedade".

Complementando as autoras supracitadas, Da Mata (2015) afirma que a construção de tais matrizes, ou elementos pedagógicos, são inerentes à vivência em movimento no MST que é composta por mobilizações e ocupações, assembleias, pela produção de vida nos assentamentos, pela luta e conquista de escolas, pela mística, o trabalho cooperado etc. Ou seja, essa construção e organização entende e pensa esses elementos como meios de desencadear processos educativos e de formação da identidade Sem Terra.

Os princípios filosóficos defendidos pelo Movimento são: educação para a transformação social que permite o desenvolvimento da consciência de classe; educação para o aumento da "densidade cultural" e capacidade de projetar-se no futuro; educação que desenvolva a "consciência organizativa" que vai além da crítica e possibilita intervenções organizadas na realidade; educação para o trabalho e a cooperação promovendo novas relações sociais; educação "omnilateral" que reintegre as diversas esferas e dimensões da vida e da formação humana; educação com valores humanistas e socialistas que rompa com os propagados pelo capitalismo; educação como processo permanente e transformador (MST, 1996).

Segundo Ramos (2016), a concepção de educação infantil do Movimento tem sua fundamentação em experiências pedagógicas socialistas e revolucionárias, como a cubana 
e a soviética, com forte influência do movimento de educação popular de Paulo Freire e de pensadores como Pistrak, Shulgin e Makarenko, consolidando também sua característica de educação internacionalista, em que inspira-se em práticas revolucionárias e transformadoras além de solidarizar-se com outras causas e lutas.

Em Paulo Freire observamos sua disposição revolucionária de erradicar o analfabetismo por meio das experiências de educação popular desenvolvidas entre as décadas de 50 e 60 no país. Proposta essa que libertou um número significativo de sujeitos da escuridão e isolamento causados pela ignorância, porém, não acabou com o problema. Poderia, mas não era interessante por parte do governo eliminar os currais eleitorais, tão pouco "munir" os sujeitos com educação.

Era preciso transcender as fronteiras da alfabetização da palavra escrita para que ela se tornasse um instrumento de desalienação e de formação do cidadão como indivíduo portador de vontade própria, capaz de operar a modificação de sua realidade e também da realidade coletiva, pois é sujeito de pensamento autônomo. (TIEPOLO, 2015, p. 27177).

A influência de Freire na proposta educacional do MST pode ser constatada na própria práxis; no trabalho com temas geradores; na escolha intencional de conteúdos, contrariando a ideia de neutralidade na educação e evidenciando a dimensão política do processo; na realidade como ponto de partida para o processo de ensino e no respeito aos saberes dos educandos; na educação como processo permanente e transformador que ocorre nas relações entre as pessoas mediatizadas pelo mundo, na valorização da cultura popular como aspecto emancipatório; na construção e apropriação de uma consciência capaz de "ler o mundo" e emancipar sujeitos.

Os pedagogos socialistas Moisey M. Pistrack e Viktor N. Shulgin compartilhavam em seus ideais educacionais a questão do trabalho, da atualidade, da autogestão e autoorganização dos alunos para questões relacionadas a organização do trabalho pedagógico nas Escolas Comunas, regidas pelos princípios da Escola Única do Trabalho (SANTOS; PALUDO, 2015). Freitas (2012 apud SANTOS e PALUDO, 2015, p. 1178) esclarece que tais princípios explicitavam a ideia de uma escola "comprometida com a construção de uma nova sociedade, sendo instrumento a favor da conscientização e emancipação da classe trabalhadora" por meio do trabalho como princípio educativo e da formação politécnica. 
De acordo com Santos e Paludo (2015) a necessidade de transformar e articular o trabalho com os estudos e a vida criou a expressão do trabalho socialmente útil. De acordo com as autoras, o desejo de Pistrack era o de "propiciar aos alunos a compreensão da totalidade do mundo do trabalho", "desde as suas mais simples formas (trabalho individual no autosserviço, cuidados pessoais) até as mais complexas possíveis (trabalho na fábrica)", por meio da participação (prática) e do "estudo de toda a modernidade, até as manifestações mais elevadas de cultura, como superestruturas em cima de interrelações econômicas" de trabalho.

O MST entende que a participação é a aprendizagem da democracia, que acontece "através do relacionamento diário dos alunos com os alunos, dos alunos com os professores, dos professores com os professores, da escola com o assentamento" (MST, 1999b, p. 15). Desse modo, o Movimento afirma que "Aprender a decidir. Aprender a respeitar o outro. Aprender a respeitar as decisões do coletivo. Executar o que foi decidido em conjunto. Isto é participação. Isto é democracia” (MST, 1999b, p. 15).

Segundo Pistrack (2011), o coletivo infantil inculca nas crianças a iniciativa coletiva, a responsabilidade correspondente à sua atividade, suscitando quase que naturalmente a auto-organização. Entretanto, ressalta que a escola tem papel de despertar, organizar e ampliar o interesse nas crianças de modo a inseri-los na dimensão social. "A escola deve transformar os interesses individuais, as emoções das crianças, em fatos sociais, cimentando com base nisso o coletivo infantil" (p. 144). Dessa forma, os coletivos são formados pela união e semelhança por determinados interesses que lhes são próximos. No entanto, "a escola só permitirá um amplo desenvolvimento e uma coesão íntima do coletivo das crianças no momento em que for o lugar (e o centro) da vida infantil, e não apenas o lugar de sua formação" (PISTRACK, 2011, p. 144).

\section{Os mecanismos e instrumentos de participação democrática nas escolas do MST}

$\mathrm{O}$ direito à participação das crianças acontece via mecanismos existentes na estrutura social do Movimento e estrutura orgânica das escolas do MST. Torna-se formativo a medida que é exercido, ou seja, que se participa da organização coletiva de tempos e espaços intencionalmente planejados para a prática social e exercício da democracia. 
As escolas do MST possuem uma estrutura orgânica responsável por organizar a gestão da escola e garantir: o princípio da gestão democrática; a auto-organização dos alunos; os coletivos pedagógicos das educadoras(es) e a participação da comunidade que representa o MST. Também possuem instrumentos de gestão que contribuem para a organização coletiva e para os processos de ensino-aprendizagem da escola. Os instrumentos de gestão apresentados nessa proposta são: regulamento interno, planejamento coletivo e avaliação coletiva (MST, 1999c).

Pegamos como exemplo uma estrutura orgânica sugerida para escolas do ensino fundamental para exemplificar os mecanismos que materializam o princípio da gestão democrática, bem como os instrumentos de gestão elaborados coletivamente que contribuem para a qualidade dos processos formativos e pedagógicos. Tal estrutura encontra-se no Caderno de Educação $N^{0}$ 9, intitulado "Como fazemos a Escola de Educação Fundamental” (MST, 1999c). A sugestão contempla as muitas formas de autoorganização e participação das crianças nas instâncias da escola.

Segundo o Movimento (MST, 1999c), os sujeitos principais que compõem a base da estrutura orgânica da escola são: os educandos, as educadoras(es), a comunidade, as instâncias do MST e sua relação com as Instâncias da escola.

Os educandos se organizam em coletivos, cada qual com seu papel e sua responsabilidade dentro do conjunto da escola. Dentre as quais podemos destacar:

- Grupos de Atividades (GAs): também podem ser chamados de Núcleos de Base (NBs) assim como nos assentamentos e acampamentos. Cada sala de aula se autoorganiza em grupos de cinco participantes, dentre estes se escolhe um coordenador. Os coordenadores dos grupos escolhem quem será o coordenador da sala, seu substituto e secretário. O ideal é que esse processo aconteça a cada dois meses para todos na medida do possível possam dirigir e serem dirigidos, representar a todos e serem representados. Os alunos são acompanhados por uma educadora (orientadora ou regente). Os GAs são responsáveis por executar várias tarefas e atividades como: debate e leitura do Jornal Sem terra; organização e limpeza da sala de aula; embelezamento da escola; distribuição da merenda; limpeza das partes comuns da escola (banheiros, corredores, etc.); ajudar no aprendizado em sala de aula (monitorias); preparar a mística etc (MST, 1999c).

- Grupos Sala Aula (SAs): é composto pelos coordenadores de sala (eleitos pelos GAs). São responsáveis por promover assembleias dos educandos elaborar normas de 
convivência em sala de aula; avaliar o processo educativo; propor trabalhos voluntários; debater os rumos da escola, entre outros. A assembleia dos educandos que avalia e delibera sobre os processos educativos pode acontecer da seguinte forma: 1) cada educando aponta por escrito críticas e propostas que são depositadas em uma caixa. Para que tenham validade e sejam considerados, estes devem estar identificados. 2) o SA se reúne com a educadora Orientadora e elaboram a pauta da assembleia, levando em conta os bilhetes identificados. Debatem e formulam respostas para os problemas apontados. 3) no dia da assembleia, o SA da turma apresenta os assuntos um por um e caso seja necessário pede esclarecimentos a quem escreveu o bilhete. Passada a palavra para os demais, são apresentadas as propostas de ação e juntos decidem sobre seu encaminhamento. O secretario do SA pode ficar responsável pela ata da assembleia. Os SA podem participar das instâncias da escola deliberando em assembleias, plenárias e coordenação da escola (MST, 1999c).

- Brigadas de Trabalho: composta por vários membros de GAs e SAs. Esta frente é responsável pela Unidade de Produção da escola (MST, 1999c).

As educadoras(es) nesta estrutura são todas as pessoas envolvidas diretamente no processo aprendizagem-ensino da escola. Ou seja, os educadores(as) da escola são: professores; funcionários; voluntários e técnicos. Esse grupo se organiza em Coletivos Pedagógicos (ou também chamados de Coletivo de Educadoras(es). Tem por objetivo: avaliar o processo educativo, avaliar sua postura; planejar processos e aprimorar seu acompanhamento; participar da Coordenação da Escola etc. Para este coletivo a escola deve: prever tempos em seu calendário para reuniões; estabelecer contato com o Setor de Educação do MST e buscar a socialização das experiências com outras escolas. Os coletivos pedagógicos relacionam-se diretamente com o Setor de Educação do MST por meio da Coordenação Pedagógica. O Coletivo participa das deliberações da escola por meio das Assembleias e da Coordenação da Escola (MST, 1999c).

- Equipes de Educação: cada acampamento e assentamento deve ter uma Equipe, ou Coletivo ou Setor de Educação que se preocupe com os processos educativos e culturais da comunidade e acompanhe a escola garantindo vínculo com a organicidade do MST, bem como garantir que o Conselho da Escola cumpra sua tarefa no processo de gestão democrática da escola (MST, 1999c). 
- Voluntários: a comunidade pode se organizar para prestar ou indicar: monitores em oficinas e unidades de produção; orientadores para o tempo esporte e pessoas que possam participar das atividades pedagógicas no caso de substituições de professores (MST, 1999c).

As instâncias da escola constituem-se como espaços de participação que respeitam a organização e as orientações do MST. Por meio desses espaços de inter-relação entre sujeitos, todos contribuem na elaboração e direção do projeto político pedagógico da escola. São elas:

- Assembleia: instância máxima de gestão em que todos participam. Pode ocorrer semestralmente objetivando examinar e/ou aprovar a prestação de contas; eleger ou ratificar indicados ao Conselho de Escola; aprovar o Projeto político Pedagógico da escola; aprovar a base curricular; aprovar o Regimento Interno da escola; aprovar o calendário escolar; eleger a Direção da escola entre outros (MST, 1999c).

- Conselho de Escola: responsável por acompanhar o cotidiano da escola, por um ou dois anos (tempo de mandato). É composto por representantes das turmas de alunos, das educadoras, comunidade e MST (representado por Equipe ou Setor de Educação) (MST, 1999c).

- Plenárias: instância interna ao Conselho de Escola que pode convocar educandos e comunidade. Deliberam sobre as unidades de produção a serem implantadas, contribuem para a definição de conteúdos disciplinares, dos focos e eixos temáticos (MST, 1999c).

- Coordenação da Escola ou Direção: a Direção da escola é eleita pelos educandos, educadoras e comunidade. No entanto, pode assumir a forma de Coordenação quando assumido o princípio de direção coletiva, que amplia o espaço de participação para representantes de todos os educandos em conjunto com membros do Conselho de Escola (MST, 1999c).

De acordo com Morissawa (2001, p. 208-209), o MST possui instâncias de representação que se tornaram espaços políticos de análise e debate de linhas políticas gerais de atuação de suas Frentes de Trabalho. As Instâncias do MST são: 1)Congresso Nacional; 2)Encontro Nacional; 3)Coordenação Nacional; 4) Direção Nacional;
5)Encontros
Estaduais;
6)Coordenações
Estaduais;
7)Direções
Estaduais; 
8)Coordenações Regionais; 9)Coordenação de Assentamentos e Acampamentos; 10)Grupos de Base.

A autora ainda apresenta as Frentes de Trabalho Educacionais que compõem todos os níveis educacionais de atuação do Movimento. São elas: ensino fundamental; EJA; educação infantil; formação de educadores, cursos de Magistério e Pedagogia; ensino médio, formação técnica administrativa (MORISSAWA, 2001). As Instâncias do Movimento definem a Frente de Trabalho da Educação Infantil e seus Setores de Educação, e atuam diretamente na estrutura orgânica das escolas, subsidiando todo o trabalho pedagógico e articulando-o com outras escolas.

O funcionamento adequado dessa lógica organizativa precisa garantir espaços de participação em todos os níveis. Ou seja, para que se alcance os resultados esperados é necessário haver organicidade, sincronia para que as decisões fluam rapidamente por entre as instâncias, em movimentos ascendentes e descendentes (CALDART, 2012a).

Dessa forma, buscamos explicitar alguns dos mecanismos e instrumentos que o Movimento utiliza para viabilizar processos educativos comprometidos com a participação e exercício da cidadania e democracia para o conjunto de trabalhadores do campo e da cidade, sobretudo, para a formação dos Sem Terrinha.

\section{Considerações Finais}

A Pedagogia do MST resulta em uma síntese pedagógica que revela o compromisso social do Movimento em pensar a educação e a escola como parte dos processos de transformação da realidade e de desenvolvimento humano. Busca renovar seus processos pedagógicos de modo a atender as necessidades humanas em suas diversas dimensões, bebendo da fonte de autores e pedagogos comprometidos com valores humanísticos e ideais revolucionários. Compreende as contradições e transformações históricas atendo-se para suas implicações na atualidade e enxerga nos conflitos e nas diferenças as potencialidades formativas para seus sujeitos e para o fortalecimento de sua identidade cultural e histórica, na esperança de um futuro melhor para o conjunto da sociedade.

O Movimento ao articular a luta pela Reforma agraria com a luta por escolas e educação, busca promover por meio de seus processos organizativos a participação de 
todos na luta por direitos, justiça e dignidade junto ao Estado pressionando-o para que políticas públicas sejam efetivadas. A visibilidade e escuta conquistada pelas crianças por meio da organização de coletivos infantis é fundamental para a continuidade da luta e conquista de direitos para a infância do campo e da cidade, e consequentemente para o projeto de sociedade idealizado e almejado coletivamente pelo Movimento. A importância dada à coletividade educadora nesse processo, à compreensão e participação de todos de forma coerente com esse projeto que envolve a educação das crianças revela a humildade e o respeito que deve existir na relação ensino e aprendizagem, colocando todos na condição de aprendizes, todos na condição de sujeitos capazes de transformarse transformando sua realidade, seu destino, sua história.

Dessa forma, embora existam muitos desafios em relação a implementação da proposta de Educação do Campo, bem como para a efetivação da Pedagogia do Movimento nas Escolas do MST, a proposta é coerente com os princípios defendidos e com o discurso político e social materializado na luta. No que diz respeito ao princípio da gestão democrática presente na proposta pedagógica do MST para a educação infantil, constatamos que o mesmo materializa-se como um direito à participação social das crianças. A proposta avança na medida em que também se caracteriza como um princípio formativo que conforma sujeitos Sem Terrinha, lutadores do povo e cidadãos de uma nova ordem social mais justa e igualitária.

\section{REFERÊNCIAS}

ARENHART, Deize. Infância, Educação e MST: quando as crianças ocupam a cena. Chapecó: Argos, 2007.

ARROYO, M. G.; CALDART, R. S.; MOLINA, M. C. (Orgs.). Por uma educação do campo. 5 ed. Petrópolis, RJ: Vozes, 2011.

BARBOSA, M. C. S. et al. Oferta e demanda da educação Infantil no campo. $1^{\circ}$ ed. Porto Alegre: Evangraf, 2012.

BRASIL. Instituto Nacional de Estudos e Pesquisas Educacionais Anísio Teixeira. Ministério da educação. Censo Escolar da Educação Básica 2016 - Apresentação das Notas estatísticas. Brasília: INEP/ MEC: Fevereiro de 2017a. Disponível em: $<$ http://portal.inep.gov.br/censo-escolar $>$ Acesso em: 28/04/2017. 
BRASIL. Instituto Nacional de Estudos e Pesquisas Educacionais Anísio Teixeira. Ministério da educação. Censo Escolar da Educação Básica 2016 - Notas Estatísticas. Brasília: INEP/ MEC: Fevereiro de 2017b. Disponível em:

$<$ http://portal.inep.gov.br/censo-escolar> Acesso em: 28/04/2017.

BRASIL. Lei Darcy Ribeiro (1996). Lei no 9.394, de 20 de dezembro de 1996. LDB: Lei de Diretrizes e Bases da Educação Nacional. Estabelece as diretrizes e bases da educação nacional. 13. ed. Brasília: Câmara dos Deputados, Edições Câmara, 2016. (Série legislação ; n. 263 PDF) Disponível em: < http://bd.camara.gov.br/bd/handle/bdcamara/19339 >

BRASIL. Constituição (1988). Constituição da República Federativa do Brasil. Brasília: Câmara dos Deputados, Edições Câmara, 35. ed. 2012. Biblioteca digital da Câmara dos Deputados. Disponível em:< http://bd.camara.gov.br $>$

BRASIL. Ministério Da Educação. Conselho Nacional De Educação. Câmara De Educação Básica. Resolução No 2, de 28 de Abril de 2008. Estabelece diretrizes complementares, normas e princípios para o desenvolvimento de políticas públicas de atendimento da Educação Básica do Campo. Disponível em: $<$ http://portal.mec.gov.br $>$

BRASIL. Ministério da Educação. Secretaria de Educação Continuada, Alfabetização e Diversidade. PARECER CNE/CEB No: 23/2007. Aprovado em: 12/9/2007. Relator: Murílio de Avelar Hingel. Consulta referente às orientações para o atendimento da Educação do Campo. Disponível em: $<$ http://portal.mec.gov.br $>$

BRASIL. Conselho Nacional De Educação. Câmara De Educação Básica. Resolução CNE/CEB N $^{\circ}$ 1, de 3 de Abril de 2002. Institui Diretrizes Operacionais para a Educação Básica nas Escolas do Campo. Disponível em:< http://portal.mec.gov.br >

BRASIL. Câmara de Educação Básica do Conselho Nacional de Educação. Parecer CNE/CEB no 36/2001. Aprovado em: 04/12/2001. Relatora: Edla de Araújo Lira Soares. Diretrizes Operacionais da Educação Básica para as Escolas do Campo. Disponível em: < http://portal.mec.gov.br/cne/arquivos/pdf/pceb36_01.pdf >.

CALAZANS, M. J. C. Para compreender a educação do Estado no meio rural - Traços de uma trajetória. In: THERRIEN, J.; DAMASCENO, M. N. (coords.) Educação e Escola no Campo. Campinas: Papirus, 1993. p. 15-39.

CALDART, R.S. et al. Escola em Movimento: Instituto de Educação Josué de Castro. São Paulo: Expressão Popular, 2013.

CALDART, Roseli Salete. Pedagogia do Movimento Sem Terra. 4 ed. São Paulo: Expressão Popular, 2012a.

CALDART, Roseli Salete (Orgs.). Dicionário da Educação do Campo. Escola

Politécnica de Saúde Joaquim Venâncio. RJ, SP: Expressão Popular, $2012 b$. 
CALDART, R. S. Educação do Campo. In: CALDART, R. S. (Orgs.) Dicionário da Educação do Campo. Escola Politécnica de Saúde Joaquim Venâncio. RJ, SP: Expressão Popular, 2012b. P. 259-267.

CALDART, R.S. Educação do campo: notas para uma análise de percurso. Trabalho, Educação e Saúde, Rio de Janeiro, v.7, n.1, p.35-64, mar./jun. 2009.

CALDART, R. S. Coletivo Nacional de Educação do MST; Instituto Técnico de Capacitação e Pesquisa da Reforma Agrária (ITERRA). Movimento Sem Terra: lições de Pedagogia. Currículo sem Fronteiras, v.3, n.1, pp. 50-59, Jan./Jun. 2003. Disponível em: $<$ www.curriculosemfronteiras.org $>$

CALDART, R. S. Coletivo Nacional de Educação do MST, Instituto Técnico de Capacitação e Pesquisa da Reforma Agrária (ITERRA). A escola do Campo em Movimento. I Encontro Nacional de Educadoras e Educadores da Reforma Agraria. Currículo sem Fronteiras, v. 3, n. 1, p. 60-81. Jan/Jun. 2003. Disponível em: $<$ www.curriculosemfronteiras.org $>$

CHIZZOTTI, Antonio. Pesquisa em ciências humanas e sociais. 6 ed. São Paulo: Cortez, 2003. (Biblioteca da educação. Série 1. Escola; v. 16).

DA MATA, Liene Keite de Lira. Os Sem Terrinha no Movimento dos Trabalhadores Rurais sem Terra (MST). Dissertação (Mestrado em Educação) Universidade Estadual Paulista, Faculdade de Filosofia e Ciências. Marília, 2015.

DAL RI, N. M.; VIEITEZ, C. G. Gestão democrática na escola pública: Escola Construindo Caminho. Revista Educação Unisinos. v. 14, n. 2. Mai./ago. 2010. Disponível em:< http://revistas.unisinos.br/index.php/educacao/article/view/497 >

DAL RI, N. M; VIEITEZ, C.G. Educação democrática e trabalho associado no movimento dos trabalhadores rurais sem terra e nas fábricas de autogestão. São Paulo: Ícone: FAPESP, 2008.

DAL RI, N. M; VIEITEZ, C.G. A educação do Movimento dos Sem Terra. Revista Brasileira de Educação. mai./ago., n.26, 2004. p.44-57.

FERNANDES, B. M. Os Campos da Pesquisa em Educação do Campo: Espaços e Território como Categorias Essenciais. O Campo da Educação do Campo. I Encontro Nacional de Pesquisa em Educação do Campo. Brasília, set. 2005. Disponível em:< http://portal.mec.gov.br >. Acesso em: 30 mar. 2015.

FRANCISCO, M.V.; ALANIZ, E.P. Interfaces entre a Educação do campo e a disciplina de Educação física escolar. Reflexão e Ação, Santa Catarina, v.22, 2014. p.39-64 
GIL, Antônio Carlos. Métodos e técnicas de pesquisa social. 6 ed. São Paulo: Atlas, 2008.

MORISSAWA, Mitsue. A História da luta pela terra e o MST. São Paulo: Expressão Popular, 2001.

MST. Movimento Dos Trabalhadores Rurais Sem Terra. Princípios da Educação no MST. Caderno de Educação N 08 - Porto Alegre: Coletivo Nacional do Setor de Educação. Julho, 1996.

MST. Movimento dos Trabalhadores Rurais Sem Terra. Como fazer a escola que queremos. Caderno da Educação No 1.2 ed. Setor de Educação. Janeiro, 1997b.

MST. Movimento dos Trabalhadores Rurais Sem Terra. O que queremos com as escolas dos assentamentos. Caderno de Formação $\mathrm{N}^{0}$ 18. 3 ed. Setor de Educação. Março, 1999b.

MST. Movimento dos Trabalhadores Rurais Sem Terra. Como fazemos a escola de Educação Fundamental. Caderno de Educação No 9. Setor de Educação. Novembro, 1999c.

PASUCH, J.; SANTOS, T. M. D. A importância da Educação Infantil na constituição da identidade das crianças como sujeitos do campo. In:

BARBOSA, M. C. S. et al. Oferta e demanda da educação Infantil no campo. $1^{\circ}$ ed. Porto Alegre: Evangraf, 2012.p. 107-151.

PISTRACK, M. M. Fundamentos da escola do trabalho. 3 ed. São Paulo: Expressão Popular, 2011.

QUEIROZ, J. B. P. A educação do campo no Brasil e a construção das escolas do campo. Revista Nera, Ano 14. no 18. Presidente Prudente, Jan./Jun. 2011. p.37-46.

RAMOS, M. N.; MOREIRA, T. M.; SANTOS, C. A. (coords). Referenciais para uma Política Nacional de Educação do Campo. Caderno de Subsídios, Brasília: Secretaria de Educação Média e Tecnológica, Grupo Permanente de Trabalho de Educação do Campo. Fevereiro de 2004.

RAMOS, Marcia Mara. Educação, Trabalho e Infância: contradições, limites e possibilidades no Movimento dos Trabalhadores Sem Terra. (Dissertação de mestrado). Campinas, SP. 2016.

RIBEIRO, M. Educação do campo: embate entre movimento camponês e Estado. Educação em Revista, Belo horizonte, v. 28, n.01, mar. 2012. p.459-490.

ROSSETTO, E. R. A. Essa ciranda não é minha só, ela é de todos nós: A educação das crianças sem-terra no MST. (Dissertação de mestrado). Campinas, SP. 2009. 
SANTOS, F. H. T.; SOUZA, M. A. Educação do campo e MST. Ponta Grossa: Olhar de Professor, 2007. P.211-226. Disponível em: <http://www.uepg.br/olhardeprofessor > Acesso em 14/04/2017.

SANTOS, Franciele Soares; PALUDO, Conceição. A atualidade das contribuições de Moisey M. Pistrack e Viktor N. Shulgin para a pedagogia do Movimento os Trabalhadores Sem Terra. Perspectiva, Florianópolis, v. 33, n. 3, p. 1163-1183, set./dez. 2015. Disponível em:

$<$ https://periodicos.ufsc.br/index.php/perspectiva/article/view/33573>Acesso em: 29/05/2017.

SILVA, L. H.; MORAIS, T. C.; BOF, A. M. A educação no meio rural do Brasil: revisão da literatura. In: BOF, Alvana Maria. (Org.) A educação no Brasil rural. Brasília: Instituto Nacional de Estudos e Pesquisas Educacionais Anísio Teixeira, 2006.

SOUZA, Maria Antônia. Educação do campo: políticas, práticas pedagógicas e produção científica. Educação \& Sociedade, Campinas: Unicamp, v.29, n.105, set./dez., 2008. Disponível em: < http://www.scielo.br > Acesso em: 01 ago. 2014.

TIEPOLO, Elisiani Vitória. Paulo Freire e a luta pela educação no MST. XII Congresso Nacional de Educação - EDUCERE/ PUC-PR. 2015. p. 27174-27185. Disponível em: < http://educere.bruc.com.br/arquivo/pdf2015/20854_11371.pdf > 